\title{
Analysis of the social, cultural, economic and environmental impacts of indigenous tourism: a multi-case study of indigenous communities in the Brazilian Amazon
}

\author{
C. N. Brandão ${ }^{1}$, J. C. Barbieri ${ }^{1}$ \& E. Reyes Junior ${ }^{2}$ \\ ${ }^{1}$ Fundação Getulio Vargas - EAESP/FGV, Brazil \\ ${ }^{2}$ Universidade Federal de Roraima - UFRR, Brazil
}

\begin{abstract}
Indigenous tourism does not yet figure on the agenda of public tourism policies in Brazil, neither is it regulated. There are, however, various tourism initiatives in indigenous areas throughout the country, mainly in the Amazon region, where most of Brazil's Indian population is concentrated. Considering tourism can lead to both positive and negative consequences the objective of this work is to analyze the social, cultural, economic and environmental impacts of tourism on Indian communities in the Brazilian Amazon region. A survey was carried out that comprised forty questions that were answered by Indians from the communities. The study revealed that tourist activities have proved to be sustainable in their social, cultural and environmental dimensions, according to the opinion of the local inhabitants. However, the result for economic sustainability was not representative, perhaps because the communities receive a reduced number of visitors because of their incipient infrastructure.
\end{abstract}

Keywords: sustainable tourism, indigenous tourism, tourism sustainability indicators, sustainable development.

\section{Introduction}

Indigenous tourism is not yet a segment prioritized by the Brazilian tourism industry, neither is it regulated. There are, however, various tourism initiatives in indigenous areas throughout the country, but it is not known for certain how the activity is organized and if it really produces benefits for the Indian people, 
because there are few empirical studies on this theme, particularly in the Amazon region where most of the Indian population in Brazil is concentrated.

This research was carried out in three Indian communities: Bananal, Nova Esperança and Boca da Mata, which belong to the São Marcos Indigenous Lands, which are located in the Brazilian Amazon region. Initially, Indian people lived mainly from growing manioc, hunting and fishing, but this reality has changed over the last ten years. There is an increasingly constant search for activities that make the social, economic, cultural and environmental sustainability of the communities feasible. The Indian communities mentioned above have seen tourism as an alternative for sustainable local development. These indigenous groups have shown themselves to be active entrepreneurs, who negotiate partnerships with private companies, prepare projects for obtaining financing and have started assuming a relevant role in the structure of the sector. Starting from the premise that tourism, depending on the way in which it is carried out, can promote sustainable local development for indigenous people, the objective of the research is to analyze the social, cultural, economic and environmental impacts on indigenous communities living in the Brazilian Amazon region.

The study is justified because of the concern with the impact that tourism might have on indigenous areas if measures are not taken that include the sustainability dimensions in their development. Various academics have debated the positive and negative effects of tourism on indigenous cultures [1,2]. In the Brazilian Amazon region it is seen that the Indians have chosen tourism as an activity that is capable of providing those living in the community with autonomy while preserving their culture and traditional values.

\section{Sustainable local development}

Numerous reports have been published since the 1970s that mention the concern there is with maintaining economic growth without destroying the natural and social environment. The World Commission on Environment and Development (WCED) was created by the General Assembly of the United Nations Organization (UNO) in 1983, and its report entitled "Our Common Future", which was published in 1987, emphasizes the need for a new development model that is capable of making economic growth, wealth distribution and environmental preservation compatible. Sustainable development is defined as that which satisfies the needs and aspirations of the present, without compromising the ability of future generations to satisfy their own needs [3]. The central points on sustainable development that were presented in the "Our Common Future" report became the basis for preparing Agenda 21, which can be defined as a "planning instrument for the construction of sustainable societies in different geographic bases, which reconciles methods of environmental protection, social justice and economic efficiency" (UN Conference on Environment and Development, 1992) [4].

Segmentation by activity or by sector, as [5] highlight, is a way of operationalizing sustainable development proposals. Sustainability can be found 
in civil construction, sustainable architecture, sustainable tourism and in other economic sectors. Even though each of the dimensions are broken down to facilitate an understanding of sustained development, they cannot be developed in isolation because they are inter-related. From this perspective, the reach of sustainable local development in indigenous communities may result from the integration of tourism, provided that the planning and management of the activity are carried out in a participative way and include the strengthening of an endogenous power on the part of the communities.

\subsection{Indigenous tourism and sustainability}

It is a well-known fact that the tourism industry depends on natural and cultural resources for attracting tourists. As [6] define it, indigenous tourism is tourism in which the Indians are directly involved and the main attraction are their culture and tradition.

The concept of sustainability in tourism was initially established as a notion that there is a need to balance the inter-relationship between tourism and environment; that there must be a commitment to minimizing conflict; and that planning must be exercised in such a way that the long-term feasibility of the industry is safe-guarded [7]. Whatever the position, a common theme running through these perspectives is that the development of sustainable tourism includes a focus on achieving some level of harmony among the groups of stakeholders in order to develop long-lasting quality of life [8,9].

The [10] conceives of sustainable tourism as a process that meets the current needs of tourists and the receiving communities, without compromising the ability to meet the needs of future generations. [8] defines it as "tourism that is economically viable, but that does not destroy those resources on which tourism of the future will depend, particularly the physical environment and the social fabric of the local community". In this context, the development of sustainable tourism requires the participation of all those interested-citizens, businesspeople and community leaders - in order to guarantee there is consensus with regard to the decisions taken [11]. The focus on stakeholder participation underlines even more the capacity to deal with the various problems that crop up $[9,11,12]$.

Achieving sustainable tourism requires constant monitoring of the impacts and the introduction of preventive and/or corrective measures whenever necessary. Tourists must also be guaranteed a significant experience in order to raise their awareness of the issues of sustainability [11, 13, 14]. For this to happen, it is necessary to use accurate and reliable indicators that are capable of testifying to the sustainability of the tourism as well as its monitoring.

\subsection{Sustainable tourism indicators}

According to the [11] indicators are sets of formally selected information to be used on a regular basis in such a way as to measure important changes in the development and management of tourism. They are measures that help discover the existence and seriousness of current problems, signs of future problems, and means of identifying and measuring the results of anthropic actions in order to 
facilitate the decision-making process [15]. It is within this context that [16] adds that indicators are developed as a simplified tool that facilitates communication, serving as the basis for political decisions in the pursuit of sustainability.

Indicators normally correspond to questions relating to the natural resources of a destination, concerns with its economic sustainability, questions relating to its cultural heritage and social values and broader questions to do with the organization and management of the destination [11].

\section{Methodology}

This study is characterized as being exploratory-descriptive, since it describes and analyzes in what way the phenomenon occurs, as well as its characteristics and nature. The research strategy adopted was that of the case study, whose contribution, according to [17], is knowledge of individual, organizational, political, social, group and related phenomena, evoked by the desire to understand complex social phenomena.

The research was carried out by applying a survey, which comprised four questions adapted from the Workshop on Indicators for the Sustainable Development of Tourism, [18]. The instrument comprised two sections: one referred to the socio-demographic characteristics of those interviewed, like their age, gender, employment situation and earnings from tourism. The second checked the environmental, cultural, social and economic impacts arising from tourism in indigenous communities. A pre-test was carried out to check for clarity and understanding of the questions in the questionnaire.

The research sample was constituted by 210 valid responses. As the questionnaire consisted in 40 statements this provided a ratio of 5 cases per variable, using a 5-point interval scale (5 - I fully agree, to 1 - I totally disagree). [19] alleges that a minimum of five cases per variable is acceptable, but for greater analysis reliability it is preferable to have a proportion of more than ten cases per variable. Because of this, intrablock factor analysis was chosen, in order to evaluate the unidimensionality of the construct, as Mondadori and Ladeira (2007) mention [20]. Categorical Principal Components Analysis (CAPCA), as indicated by [21], was used. This is a method that aims to summarize a set of data in a manner that is similar to the conventional analysis model. This is an alternative option when the suppositions of linearity between variables, interval scales and normal distribution are not met.

Subsequently it was decided to compare two groups. As the normality assumption was not confirmed, a Mann-Whitney statistical test was carried out. The statistical test shows the mean-rank values that are used for identifying which of the groups had a positive opinion about sustainability in tourism in the social, cultural, environmental and economic aspects. In this case the $p$-value (Asymp. Sig.) is a criterion for defining if there are significant differences between the groups or not. The analyses were made feasible by way of the SPSS software, Version 18.0. 


\section{Results}

The first part of the questionnaire refers to the socio-demographic data and the second stage refers to the analysis of the impact of tourism on social, cultural, environmental and economic dimensions in the view of the residents. It was found that there is not a large difference between the genders in terms of the numbers of those responding. Female respondents represented $48 \%$ of the sample, while male respondents represented a little more than $51 \%$. As for the age band, it was observed that in those indigenous communities where the survey was carried out young people in the 150-25 year band represent $32.38 \%$ of the population, as shown in Figure 1. People in the 25-34 and 35-44 age bands totaled a little over $20 \%$ each. People in the $45-54$; 55-64, 65-74 and over 75 bands totaled less than $10 \%$ each.

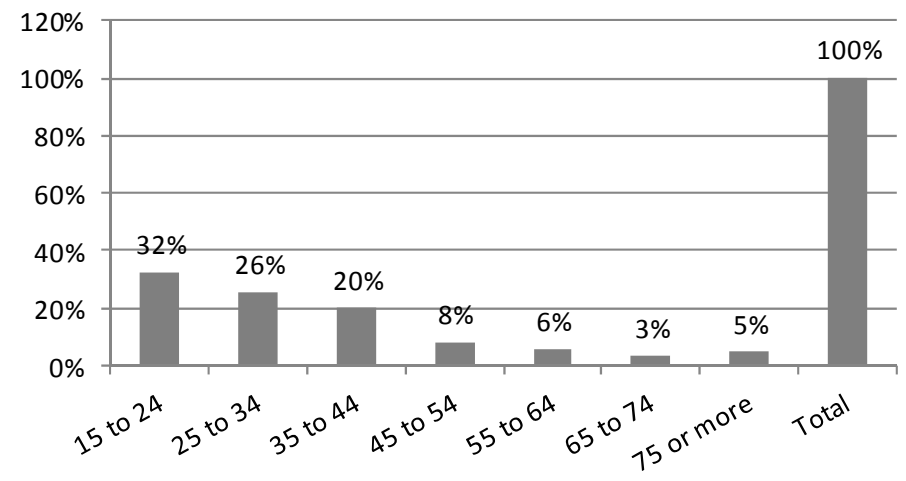

Figure 1: Age.

Community income derives predominantly from agriculture, according to $40 \%$ of the respondents. The second activity is tourism, with $33 \%$ of the replies. However, the respondents did not choose the 'tourism' option as their only activity; it is always accompanied by some other activity. In the majority of cases tourism is the second most important source of income for the respondents. This was followed by the 'Other areas' category, which totaled $14 \%$. And 'Education', which totaled 9\%. The categories 'Trade' and 'Fishing' totaled 2\% each.

As far as concerns the percentage of income coming from tourism, most of the interviewees (139 people) were unable to say how much of their income comes from tourism or they have no income from tourism, as can be seen in Figure 3. This result may seem contradictory when compared with what was presented in Figure 3, in which tourism appears as the second most practiced activity. However, less than half of the residents from the three communities are able to calculate how much of their income comes from tourism. Most, perhaps because of the sporadic nature of the activity, cannot say what percentage they 
earn from tourism. As can be seen, 39 respondents state that $5 \%$ of their income comes from tourism activities. A further 25 people said that $10 \%$ of their total income comes from tourism. Four respondents said that their income coming from tourism is $20 \%$. Finally, three respondents said that tourism corresponds to $30 \%, 50 \%$ and $80 \%$ of each of their incomes.

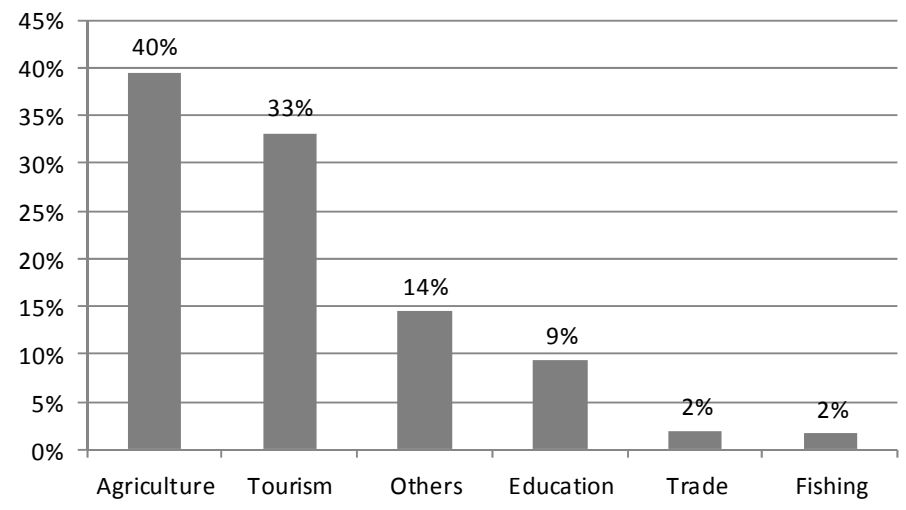

Figure 2: Area of work.

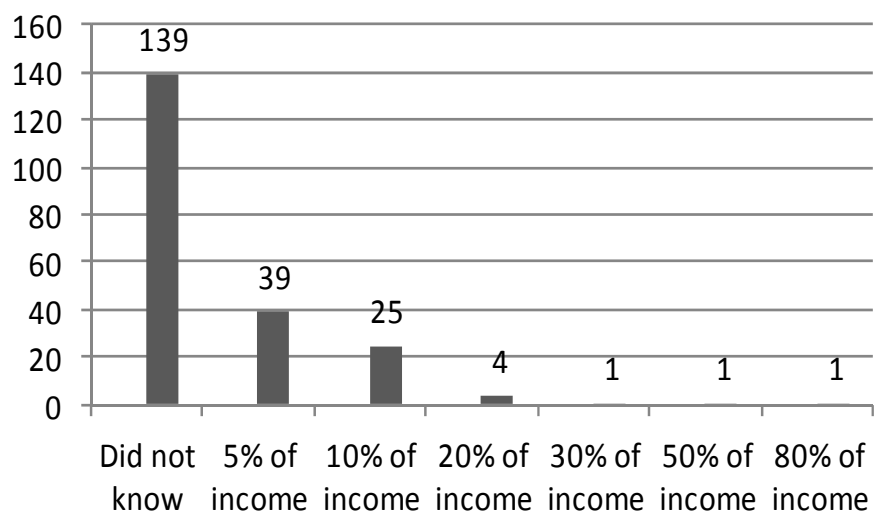

Figure 3: Percentage of income coming from tourism.

The second stage of the questionnaire refers to the intrablock Exploratory Factor Analysis (intrablock EFA), which was used to analyze the undidimensionality of the 40 statements about tourism sustainability that were placed in each of the 4 dimensions studied in the research: social, cultural, environmental and economic. Below are the analysis summary measures, which 
are: the dimension studied, Cronbach's alpha and the percentage of explained variance. It was expected that each of the dimensions would have a Cronbach's alpha over 0.6 , an eigenvalue over 1 and a variance percentage over 0.5 , according to [19]. Table 1 shows the summaries of the EFAs. All dimensions have a Cronbach's alpha over 0.6 ; an eigenvalue over 1 and a variance percentage over 0.5 .

Table 1: Intrablock Factor Analysis summary.

\begin{tabular}{l|r|r|r}
\hline \multirow{2}{*}{ Dimension } & \multirow{2}{*}{ Cronbach's alpha } & \multicolumn{2}{|c}{ Explained variance } \\
\cline { 3 - 4 } & & Eigenvalue & \% of explained variance \\
\hline Social & .695 & 2.089 & 52.22 \\
Cultural & .662 & 1.709 & 56.96 \\
Environmental & .869 & 2.874 & 71.85 \\
Economic & .725 & 2.193 & 54.84 \\
\hline
\end{tabular}

Table 2 gives the weightings of the dimensions studied. The results were significant for forming the social dimension, using four of the ten statements in the questionnaire. Three of the ten statements were used to form the cultural dimensions.

Table 2: Weightings of the dimensions.

\begin{tabular}{c|l|c}
\hline Dimension & \multicolumn{2}{|c}{ Factor loads } \\
\hline \multirow{4}{*}{ Social } & DIM_SOC2 & .718 \\
& SOC_DIM5 & .728 \\
& SOC_DIM8 & .735 \\
& SOC_DIM9 & .709 \\
\hline \multirow{3}{*}{ Cultural } & INV_CUL_DIM7 & .780 \\
& INV_CUL_DIM9 & .749 \\
& INV_CUL_DIM10 & .734 \\
\hline \multirow{5}{*}{ Environmental } & INV_AMB_DIM2 & .770 \\
& INV_AMB_DIM3 & .893 \\
& INV_DIM_AMB4 & .871 \\
& INV_AMB_DIM8 & .851 \\
\hline \multirow{2}{*}{ Economic } & ECO_DIM3 & .737 \\
& ECO_DIM4 & .899 \\
& ECO_DIM5 & .785 \\
\hline
\end{tabular}

Four of the ten statements were necessary to compose the environmental dimension. Finally, to form the economic dimensions three of the ten statements were necessary. 


\subsection{Comparison of groups}

A non-parametric Mann-Whitney test was used to test the differences between the two groups. The differences between the opinions of the respondents were analyzed, by dividing them into two groups by economic activity. The differences between agricultural activities were first analyzed and then the differences between tourism activities. With this it was possible to show the respondents' opinions with regard to which dimensions are significantly important to sustainability in tourism.

After the analyses it was seen that the respondents who are active in the agriculture area were more positive as to sustainability in tourism within the cultural dimension, as shown in Table 3, with a mean-rank value of 107.46.

Table 3: Analysis of dimensions by activity (agriculture).

\begin{tabular}{lccc}
\hline \multicolumn{1}{c}{ Agriculture } & No & Yes & Asymp. Sig. (p) \\
\hline Social dim (mean-rank) & 116.310 & 97.850 & 0.026 \\
Cultural dim (mean-rank) & 102.720 & 107.460 & 0.547 \\
Environmental dim (mean-rank) & 113.630 & 99.750 & 0.050 \\
Economic dim (mean-rank) & 110.490 & 101.970 & 0.250 \\
\hline
\end{tabular}

However, when observing the $p$-value, it can be seen that this difference is not significant between respondents. There were, however, significant differences in the social and environmental dimensions, with values of 0.026 and 0.05 respectively.

Those respondents who are active in the tourism area proved to be more positive with regard to sustainability in tourism in the cultural dimension, as can be seen in Table 4, with a mean-rank value of 120.96 .

Table 4: Analysis of dimensions by activity (tourism).

\begin{tabular}{lccc}
\hline \multicolumn{1}{c}{ Tourism } & No & Yes & Asymp. Sig. (p) \\
\hline Social dim (mean-rank) & 122.670 & 87.660 & 0.000 \\
Cultural dim (mean-rank) & 90.620 & 120.960 & 0.000 \\
Environmental dim (mean-rank) & 108.250 & 102.640 & 0.421 \\
Economic dim (mean-rank) & 105.300 & 105.700 & 0.956 \\
\hline
\end{tabular}

When observing the Asymp. Sig. value it can be seen that there is a significant difference between the respondents; in other words, for those who work in the tourism area, tourism is sustainable in the cultural dimension. There were significant differences in the social dimension, with a value of 0.000 . But the lowest mean rank value (87.66) related to the tourism area, which shows that the other areas are more positive with regard to sustainability in the social dimension. 
The social, cultural, environmental and economic dimensions were used for carrying out the group comparison tests. The scores were estimated in accordance with the categories found in the factor analyses, which generated the variables in the dimensions mentioned.

\section{Conclusions}

The intention behind carrying out this research was to verify the opinion of Indians as to the sustainability of tourism, by checking this activity's positive impacts on the social, cultural, environmental and economic dimensions. Given the results of the group comparison it was seen that tourism has had a positive impact on the indigenous communities as far as the social, environmental and cultural dimensions are concerned, according to the opinion of the residents. Results indicated that the impacts coming from tourism, according to the opinion of the residents, have been positive so far - at least in the social, cultural and environmental dimensions. However, the result for economic sustainability was not representative. One of the reasons for this result may be due to the fact that the communities have a reduced number of visitors. Generally speaking, however, it was found that there was an increase in income in indigenous communities. As several residents mentioned, this increase in income is perceived more at the individual level than collectively.

This result might be different if there was a more constant and greater flow of tourists to these locations. The [22] emphasizes that the principles of sustainability refer to an adequate balance between the environmental, economic and socio-cultural aspects of tourism, in such a way as to guarantee its long-term sustainability. According to the result as analyzed, this is not yet happening in all the dimensions in the communities surveyed.

With regard to the socio-cultural aspect the indigenous people have noticed improvements in self-esteem and in valuing the culture and an increase in the interest among the young to learn their mother tongue. Typical festivals and handicraft work have also become more popular and widely sought after. With regard to the environmental aspect there was an interest in conserving the environment, in reducing burning, in maintaining trails and in cleaning the area surrounding the community.

The Bananal, Nova Esperança and Boca da Mata communities can be considered to be emerging indigenous tourist destinations in the Brazilian Amazon region. But local government needs to intervene to regulate the activity and provide support for planning and monitoring the activity.

It is suggested that actions be prioritized that transform existing initiatives into excellent indigenous tourism destinations, thus creating the conditions needed for other communities to draw their inspiration from these models.

Finally, it is hoped that the findings of this research can contribute to a better understanding of this as yet little studied activity in Brazil, but one that represents an emerging segment of tourism and that is fast becoming a new opportunity for achieving the objectives of sustainable local development. 


\section{References}

[1] Smith, T. Welfare, enterprise, and aboriginal community: the case of the Western Australian Kimberley region. Australian Economic History Review. 46(3), 2006.

[2] Weaver, D. Indigenous tourism stages and their implications for sustainability. Journal of Sustainable Tourism. 18(1), 43-60, Jan., 2010.

[3] CMMAD - Comissão Mundial sobre Meio Ambiente e Desenvolvimento. Nosso futuro comum. 2 ed. Tradução de Our common future. 1a ed. 1988. Rio de Janeiro: Fundação Getulio Vargas, 1991.

[4] CNUMAD. Conferência das Nações Unidas para o Meio Ambiente e Desenvolvimento. Rio de Janeiro, 3-14 jun, 1992. http://www.un.org/ geninfo/bp/enviro.html, acessado em 23 de janeiro de 2012.

[5] Brandao, C. N., Barbieri, J. C., Reyes Junior, E.. O Campo de Estudo do Turismo Sustentável em Comunidades Indígenas. In: XIII Anais ENGEMA - Encontro Nacional sobre de Gestão Empresarial e Meio Ambiente. São Paulo, 2011.

[6] Hinch, T.; Butler, R. Indigenous tourism: A common ground for discussion. London: International Thomson, Business Press, 1996.

[7] Hunter, C; Green, H. Tourism and the environment: a sustainable relationship? London; New York: Routledge, 1995.

[8] Swarbrooke, J.. Turismo sustentável: conceitos e impacto ambiental. Vol.1. Tradução de Sustainable tourism management. Oxon: CABI. São Paulo: Aleph, 2000.

[9] Byrd, E. T. Stakeholders in sustainable tourism development and their roles. Tourism Review. 62(2), 2007.

[10] WTO. Making tourism more sustainable: a guide for policy makers. United Nations Environment Programme and World Tourism Organization. France; Spain, 2005.

[11] WTO. Indicators of Sustainable Development for Tourism Destinations: a Guidebook. World Tourism Organization, Madrid, Spain, 2004.

[12] Butts, T.; Singh, S. Sustainable tourism as a tool for conservation and protection of the Amazon rainforest in Guyana? Sustainable tourism. 2(2), pp.173-185, 2010.

[13] Johnston, J.; Tyrrel, J. Management exercises and trainer's note in sustainable tourism and dynamics. International Journal of Culture, Tourism and Hospitality Research. 1(4), 2007.

[14] Jayawardena, C. et al. Sustainable tourism development in Niagara Discussions, theories, projects and insights. International Journal of Contemporary Hospitality Management. 20(3), pp. 258-277, 2008.

[15] United Nations - UN. Indicators of Sustainable Development: Guidelines and Methodologies - 2001. UN: New York, 2001.

[16] Ciegis, R. et al. Theoretical Reasoning of the Use of Indicators and Indices for Sustainable Development Assessment. The Economic Conditions of Enterprise Functioning, 3(1), 2009. 
[17] Yin. R. K. Estudo de caso: planejamento e métodos. 3 ed. Porto Alegre: Bookman. 2010.

[18] WTO. Final report -Workshop on Sustainable Tourism Indicators for the Islands of the Mediterranean Kukljica, Island of Ugljan, Croatia 21-23 March, 2001.

[19] Hair JR, J.F. Fundamentos de métodos de pesquisam em administração. Tradução: Lane Belon Ribeiro. Porto Alegre: Bookman, 2005.

[20] Mondadori, M. G.; Ladeira, W. J.. Validação de um instrumento quantitativo em pesquisa de empreendedorismo e inovação: um estudo no contexto dos recursos tangíveis e intangíveis. Proc. of Anais do Encontro da Anpad, XXXI, 2007, Rio de Janeiro: Enanpad, Sep, 2007.

[21] Meulman, J. J.; Heiser, W. J. SPSS Categories 14.0. SPSS Inc. Chicago, 2005. 